\title{
Sử dụng hệ xử lý thông tin 3D và nguyên lý bán dẫn giá trị trong tìm kiếm giải pháp cho vấn đề ô nhiễm môi trường và biến đổi khí hậu ở Việt Nam
}

\author{
Khúc Văn Quý
}

Ngày 01-01-2022

\section{Bối cảnh COP26 và cam kết của Việt Nam}

COP26, hội nghị Liên Hợp Quốc về Biến đổi Khí hậu, được tổ chức tại Glasgow, Scotland đã kết thúc chưa đầy 2 tháng nhưng dư âm về tầm vóc của hội nghị sẽ còn đọng lại lâu dài. Lần đầu tiên tiên trong lịch sử 197 nước thành viên COP26 đã đồng thuận giảm dần than đá và các khoản trợ cấp nhiên liệu hóa thạch không hiệu quả.

Đầu tiên, COP là chữ viết tắt của Conference of Parties, tức là hội nghị giữa các bên. Các bên ở đây là các quốc gia tham gia Công ước Khung của Liên hiệp quốc về biến đổi khí hậu. Từ năm 1995 khi đại diện các quốc gia này vẫn họp lại mỗi năm và hội nghị năm nay là hội nghị lần thứ 26, cho nên gọi tắt là COP26.

Cùng với COP21 được tổ chức tại thủ đô Paris nước Pháp vào năm 2015, COP26 năm nay được coi là hội nghị thành công nhất trong 5 năm qua. Tại COP21, 195 nước thành viên đã nhất trí hạn chế mức tăng nhiệt độ trái đất không quá 2 độ $\mathrm{C}$ so với thời kỳ tiền cách mạng công nghiệp trong khi COP26 các nước tham gia đã đạt được sự đồng thuận lịch sử để tiến tới giảm phát thải về mức 0 , một bước cụ thể để đạt mục tiêu kiềm chế sự nóng lên của toàn cầu.

COP26 mang đến thách thức và cơ hội lịch sử cho Việt Nam, một nước đang phát triển nhưng lại là quốc gia chịu ảnh hưởng lớn bởi vấn đề môi trường và biến đổi khí hậu. Tại hội nghị lớn nhất hành tinh về biến đổi khí hậu vừa qua (2021), Thủ tướng Phạm Minh Chính đại diện cho Việt Nam cam kết trước cộng đồng quốc tế sẽ giảm phát thải dòng về 0 vào năm 2050 . Đây là cam kết mạnh mẽ thể hiện quyết tâm chính trị cao của Việt Nam trong cuộc chiến chống biến đổi khí hậu và bảo vệ môi trường.

Để góp phần làm sáng tỏ (gợi mở) phương hướng tiếp cận cho vấn đề môi trường nêu trên, bài nghiên cứu này có mục tiêu là: (1) lý giải tại sao cam kết chống biến đổi khí hậu lại quan trọng (ý nghĩa) với Việt Nam, (2) trình bày cơ sở khoa học gắn với hệ sinh thái giải pháp để giải quyết vấn đề biến đổi khí hậu và ô nhiễm môi trường tại Việt Nam.

\section{Mục tiêu và động lực bảo vệ môi trường và chống biến đổi khí hậu}

Phần này trình bày tổng quan thực trạng vấn đề biến đổi khí hậu và ô nhiễm môi trường, và tác động của chúng đến tự nhiên và con người, qua đó lý giải tầm quan trọng của sự cam kết trong việc giải quyết vấn đề môi trường.

Thứ nhất là mục tiêu (động lực) sinh tồn được thôi thúc từ tác động tiêu cực của ô nhiễm môi trường và biến đổi khí hậu. Ở phạm vi toàn cầu, biến đổi khí hậu đang tàn phá thế giới tự nhiên và con người, trong khi nhiệt độ trái đất vẫn không ngừng gia tăng. Theo báo cáo của Ủy ban Liên chính phủ về Biến đổi Khí hậu (IPCCC), nhiệt độ trái đất đã nóng dần lên, đặc biệt trong 
2 thập kỷ vừa qua (Hình 1). Năm 2017, hơn 1500 nhà khoa học từ 184 quốc gia đã ký vào thư thỉnh cầu cần chống lại biến đổi khí hậu [1]. Theo IPCC (2018), con người cũng chỉ còn khoảng 10 năm để cứu lấy trái đất [2]. Mặt khác gần đây các nhà khoa học khẳng định ngưỡng 1.5 độ C không còn là con số phỏng đoán (bàn luận) nữa mà đã là ngưỡng thật mà nhiệt độ trái đất không được vượt qua [3]. Ô nhiễm môi trường và biến đổi khí hậu gây ra tổn thất kinh tế to lớn. Theo tính toán, thiệt hại kinh tế liên quan đến năng suất mất đi có thể là 1.6 nghìn tỷ đô la hàng năm nếu mức tăng nhiệt vượt quá 2 độ $\mathrm{C}$ [4].

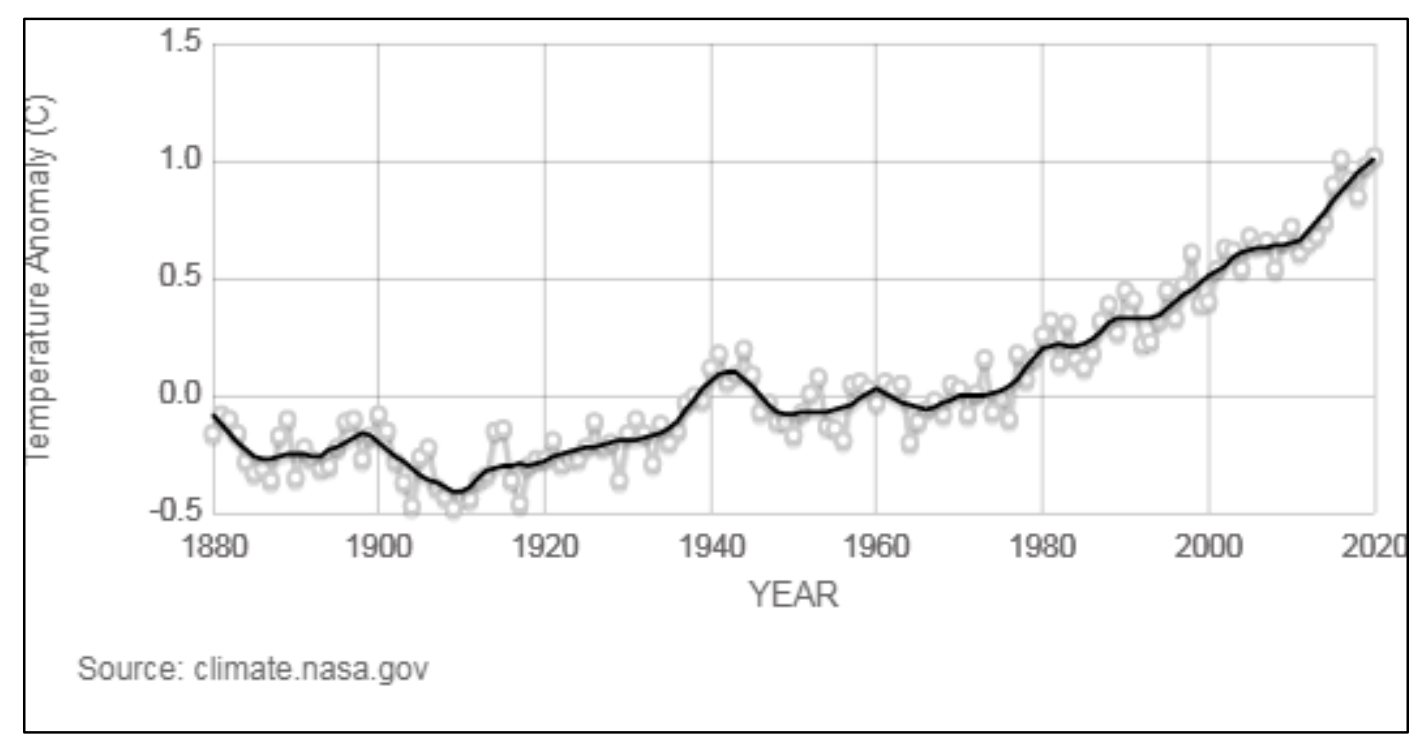

Hình 1. Nhiệt độ trái đất tăng trong giai đoạn 1880-2020. Nguồn NASA

Tại Việt Nam, ô nhiễm môi trường và biến đổi khí hậu là rất đáng lo ngại. Môi trường đất, nước, không khí đang ô nhiễm nghiêm trọng [5,6]. Ví dụ, khoảng 7,6 triệu ha đất đang chịu tác động của thoái hóa, hoang hóa dẫn tới sa mạc hóa, trong khi mỗi năm hơn 200 ngàn ha rừng mất và suy thoái [7], trong khi các thành phố lớn liên tục đạt mức ô nhiễm cao nhất thế giới. Riêng ô nhiễm không khí mỗi năm đã gây ra cái chết trực tiếp và "thầm lặng" cho 66.3 ngàn người và thiệt hại khoảng 23.8 tỷ đô la [5].

Thứ hai là mục tiêu (động lực) sản xuất kinh tế và phát triển sinh kế. Môi trường (tài nguyên) là một nguồn lực kinh tế quan trọng, và dù cho xã hội hiện đại với nền kinh tế tri thức, kinh tế số thì chúng vẫn là một yếu tố sản xuất không thể thiếu. Ví dụ, đất đai vẫn là yếu tố cho mọi hoạt động sản xuất kinh tế từ nông nghiệp cho đến công nghiệp. Nước vẫn là đầu vào cho sản xuất, trong khi gỗ (rừng) vẫn được sử dụng cho hầu hết các lĩnh vực. Ở cấp vi mô, môi trường (tài nguyên) là vốn tự nhiên của sinh kế của hộ gia đình.

Cuối cùng là mục tiêu (động lực) về sự ảnh hưởng của quốc gia. Trong bối cảnh toàn cầu hóa nhưng đan xen chủ nghĩa dân tộc, nỗ lực chống biến đổi khí hậu là nhiệm vụ chung của các quốc gia (dân tộc). Việt Nam đã dương cao ngọn cờ lương tri phẩm giá của con người đứng trước sự sống còn của nhân loại và nhận được sự tin cậy của cộng đồng quốc tế. Đây là điều kiện quan trọng để Việt Nam tranh thủ ngoại lực củng cố uy tín để hợp tác kinh tế sâu rộng với các nước trên thế giới, đồng thời cũng là điều kiện để hợp tác chia sẻ các sáng kiến giải pháp cho vấn đề an ninh môi trường và các vấn đề khác.

\section{Cơ sở khoa học của các giải pháp về vấn đề môi trường}


Để đi tìm giải pháp cho vấn đề môi trường, tác giả sử dụng (vận dụng) hệ xử lý thông tin (hệ sáng tạo) $3 \mathrm{D}[8,9]$ và nguyên lý bán dẫn (giá trị) [10]. Đây là cụm công trình được phát triển bởi Giáo sư Vương Quân Hoàng và các cộng sự trong những năm gần đây.

Trước tiên là hệ sáng tạo 3D hay còn gọi là hệ cơ chế sáng tạo. Hệ này đề cập đến 3 cách (D) để con người (cá nhân), tổ chức sáng tạo (tìm ra các giải pháp sáng tạo). $\mathrm{D}$ thứ nhất là từ những chuyên gia hàng đầu trong ngành (the best within discipline). $\mathrm{D}$ thứ hai là ngoài ngành (out of discipline), và $\mathrm{D}$ thứ ba là quá trình thực hành kỷ luật trong thời gian đủ dài (disciplined process of employing methods of creativity). Trong hệ sáng tạo 3D, hạt thông tin có ích là nguyên liệu đầu vào trước khi được "nấu và luyện" qua sự thảo luận, tranh luận, phản biện của các chuyên gia hàng đầu trong ngành và ngoài ngành, hoặc qua quá trình thực hiện kỷ luật lâu dài.

Nguyên lý bán dẫn (giá trị) đề cập đến tầm quan trọng của hạt nhân văn hóa môi trường (có giá trị thặng dư môi trường) (Hình 2). Nguyên lý chỉ ra sự không tương đồng của hai giá trị kinh tế và môi trường: giá trị môi trường có thể được hạch toán như giá trị tiền bạc, nhưng ngược lại thì không. Nguyên lý bán dẫn là cơ sở lý thuyết để đưa giá trị môi trường vào hạch toán lợi ích của sản xuất kinh doanh của doanh nghiệp và hộ gia đình trong thực tiễn trong tương lai. Bên cạnh đó, nguyên lý bán dẫn gọi giá trị môi trường là giá trị văn hóa thứ 11 và coi doanh nhân là lực lượng chủ đạo trong việc giải quyết môi trường [10].

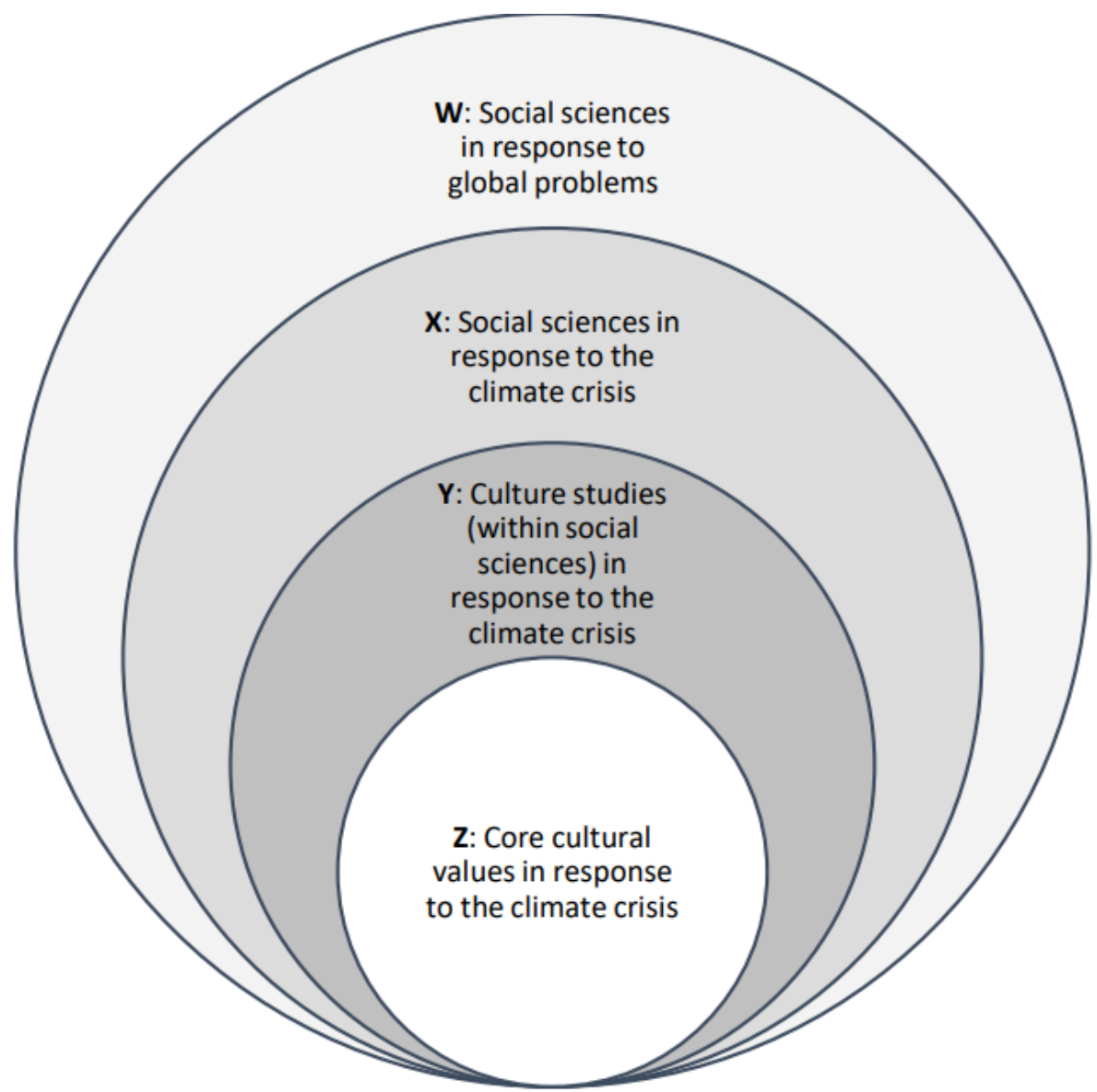

Hình 2. Lô gic giải quyết vấn đề biến đổi khí hậu và ô nhiễm môi trường dựa vào hệ giá trị văn hóa (môi trường). Nguồn [10] 


\section{Hệ sinh thái giải pháp cho vấn đề biến đổi khí hậu và ô nhiễm môi trường}

Từ hệ xử lý thông tin (hệ sáng tạo) $3 \mathrm{D}$ và nguyên lý bán dẫn giá trị, tác giả đề xuất các giải pháp (bảo vệ, cải thiện) môi trường thông qua sáu nhóm trụ cột: (1) thông tin khoa học công nghệ, (2) văn hóa môi trường, (3) phát triển kinh tế, (4) lực lượng doanh nhân có trách nhiệm môi trường, (5) hợp tác trong nước và quốc tế, (6) thực thi kỷ luật các giải pháp. Dưới đây là luận giải từng giải pháp dưới lăng kính hệ sáng tạo $3 \mathrm{D}$ và nguyên lý bán dẫn giá trị.

Thứ nhất là tăng cường thông tin, truyền thông, nghiên cứu khoa học liên quan đến môi trường. Cơ sở của giải pháp này chính là quá trình sáng tạo được bắt nguồn từ hạt thông tin hữu ích. Như được đề cập ở trên thông tin hữu ích là đầu vào của quá trình sáng tạo. Sự bùng nổ của internet, các kênh thông tin, mạng xã hội chính thống và phi chính thống giúp ích cho quá trình thông tin, truyền thông tuy nhiên cũng đặt ra nhiều thách thức trong việc kiểm duyệt và ngăn chặn những hạt thông tin bất lợi [11]. Bài toán chi phí luôn quan trọng nhưng đứng trước vấn đề ô nhiễm môi trường và biến đổi khí hậu có ảnh hưởng tới sự tồn vong của nhân loại, lĩnh vực nghiên cứu khoa học cần được thúc đẩy đầu tư hơn nữa [12].

Thứ hai là thực hiện xây dựng (chuyển đổi) văn hóa và môi trường. Văn hóa môi trường ở đây là nhận thức, thái độ, kiến thức, hành vi (bảo vệ) môi trường. Văn hóa môi trường có hạt nhân là sự gia tăng giá trị (thặng dư) môi trường (eco-surplus) và được biểu hiện thông qua sự hạch toán giá trị môi trường vào chi phí-lợi nhuận của doanh nghiệp, hộ gia đình. Văn hóa tác động đến nhận thức, hành động của con người. Xây dựng, tăng cường chuyển đổi văn hóa môi trường là giải pháp căn cơ để bảo vệ (cải thiện) môi trường. Trong giai đoạn tới, văn hóa Việt Nam cần (nên) bổ sung văn hóa thứ 11 (văn hóa môi trường) [10] để thực hiện.

Thứ ba là đẩy mạnh phát triển kinh tế để cải thiện môi trường. Phát triển kinh tế tác động lên môi trường. Một mặt phát triển kinh tế tiêu dùng (tiêu thụ) tài nguyên và tác động lên môi trường, mặt khác phát triển kinh tế tạo nguồn lực để tái thiết và hỗ trợ quá trình phục hồi sinh thái môi trường. Lý thuyết Kuznets phác họa đường suy thoái và phục hồi môi trường gắn với quá trình phát triển kinh tế qua các giai đoạn từ thấp đến cao [13]. Theo lý thuyết này, phát triển kinh tế là điều kiện quan trọng để các nước đang phát triển như Việt Nam rút ngắn quá trình chuyển đổi môi trường (từ trạng thái suy thoái đến cải thiện môi trường).

Thứ tư là tập trung xây dựng lớp doanh nhân có văn hóa môi trường (có trách nhiệm môi trường). Trong nguyên lý bán dẫn, tác giả Vương Quân Hoàng đã nêu rõ doanh nhân là lực lượng đóng góp chủ yếu cho quá trình phát thải khí nhà kính gây biến đổi khí hậu, nhưng doanh nhân cũng là lực lượng quan trọng nhất để giải quyết (cải thiện) môi trường. Thông qua nguồn lực to lớn bao gồm nhân lực, tài lực và trí lực, doanh nhân có đầy đủ điều kiện và khả năng để tham gia đề xuất và thực thi thành công các giải pháp (sáng tạo) cho vấn đề cải thiện môi trường, chống biến đổi khí hậu.

Thứ năm là mở rộng sự hợp tác (quốc tế). Dưới hệ thức sáng tạo $3 \mathrm{D}$, sự hợp tác thúc đẩy quá trình tạo thông tin (out-of-discinpline) thúc đẩy tìm ra các giải pháp khoa học về môi trường. Xét về lợi ích kinh tế, sự hợp tác khai thác hiệu quả lợi thế tuyệt đối và lợi thế tương đối giữa các quốc gia, gia tăng phúc lợi của các nước thành viên. Như đã đề cập ở trên kinh tế phát triển là điều kiện để thực thi các giải pháp môi trường. Sự hợp tác giúp gia tăng sự đồng thuận, giải quyết các khác biệt để thực thi các nguyên tắc, giải pháp môi trường mang tính toàn cầu.

Cuối cùng là thực thi kỷ luật các giải pháp đã nêu ở trên. Đây là giải pháp của mọi giải pháp. Việc thực thi, thực hành một cách kỷ luật các giải pháp không chỉ mang lại kết quả của từng 
hoạt động đã đề ra mà, dưới lăng kính hệ 3D, là điều kiện tiên quyết để tạo ra các giải pháp hữu ích, sáng tạo.

Tóm lại, giải quyết biến đổi khí hậu và ô nhiễm môi trường đang và sẽ là thách thức lớn của nhân loại trong thế kỷ 21. Con người không còn nhiều thời gian để sửa chữa, phục hồi đưa hệ sinh thái môi trường (tự nhiên) trở về trạng thái an toàn. Trong khi các nỗ lực trong thời gian qua chưa thực sự hiệu quả thì COP26 mở ra cơ hội lớn để nhân loại tiến gần đến mục tiêu kiềm chế nhiệt độ của trái đất không vượt quá 1.5 độ $C$. Mặc dù Việt Nam cùng với 146 quốc gia trên thế giới đã có cam kết mạnh mẽ nhất trong việc giảm phát thải vào năm 2050 , tuy nhiên việc cụ thể hóa cam kết thông qua các giải pháp sáng tạo là rất quan trọng. Sử dụng (áp dụng, vận dụng) hệ sáng tạo $3 \mathrm{D}$ và nguyên lý bán dẫn giá trị, tác giả đề xuất hệ sinh thái giải pháp trụ cột cần thực hiện gồm có tăng cường thông tin, truyền thông về môi trường (biến đổi khí hậu, ô nhiễm môi trường...); xây dựng, chuyển đổi và nâng cao văn hóa và môi trường; đẩy mạnh phát triển kinh tế gia tăng phúc lợi; xây dựng (chuyển đổi) lớp doanh nhân có văn hóa, trách nhiệm môi trường; tăng cường mở rộng sự hợp tác quốc tế về mọi mặt đặc biệt là trong lĩnh vực kinh tế, truyền thông và khoa học; và tăng cường thực thi các giải pháp nêu trên một cách kỷ luật.

\section{Lời cám ơn}

Tôi xin chân thành cám ơn Giáo sư Vương Quân Hoàng về sự giúp đỡ quý báu của ông trong quá trình hình thành ý tưởng và hoàn thiện bài báo.

\section{Tài liệu tham khảo}

[1] Nicole, M. (2017). More than 15,000 scientists from 184 countries issue "warning to humanity.” CBC. https://www.cbc.ca/news/science/15000-scientists-warning-tohumanity-1.4395767

[2] IPCC. (2018). We have 12 years to limit climate change catastrophe. Theguardian. https://www.theguardian.com/environment/2018/oct/08/global-warming-must-notexceed-15c-warns-landmark-un-report

[3] Fiona Harvey. (2021). Climate experts warn world leaders 1.5C is 'real science', not just talking point. Theguardian.

https://www.theguardian.com/environment/2021/oct/30/climate-experts-warn-worldleaders-15c-is-real-science-not-just-talking-point

[4] Hà, H. (2021). Biến đổi khí hậu gây thiệt hại nặng nề về kinh tế. Tạp Chí Cộng Sản. https://dangcongsan.vn/the-gioi/nhung-van-de-toan-cau/bien-doi-khi-hau-gay-thiethai-nang-ne-ve-kinh-te-599749.html

[5] Vuong, Q., Phu, T. V., Le, T. T., \& Khuc, Q. Van. (2021). Exploring Inner-City Residents' and Foreigners' Commitment to Improving Air Pollution: Evidence from a Field Survey in Hanoi, Vietnam. Data, 6(39). https://doi.org/10.3390/data6040039

[6] Van Khuc, Q., Phu, T. V., \& Luu, P. (2020). Dataset on the Hanoian suburbanites' perception and mitigation strategies towards air pollution. Data in Brief, 33, 106414. https://doi.org/10.1016/j.dib.2020.106414

[7] Khuc, Q. Van, Tran, B. Q., Meyfroidt, P., \& Paschke, M. W. (2018). Drivers of deforestation and forest degradation in Vietnam: An exploratory analysis at the national level. Forest Policy and Economics, 90, 128-141. https://doi.org/10.1016/j.forpol.2018.02.004 
[8] Vuong, Q. H., \& Napier, N. K. (2014). Making creativity: the value of multiple filters in the innovation process. International Journal of Transitions and Innovation Systems, 3(4), 294. https://doi.org/10.1504/ijtis.2014.068306

[9] Napier, N. K., \& Vuong, Q. H. (2013). Serendipity as a strategic advantage?. In: Wilkinson (ed.) Strategic Management in the 21st Century (pp. 175-199). Praeger/ABC-Clio.

[10] Vuong, Q.-H. (2021). The semiconducting principle of monetary and environmental values exchange. Economics and Business Letters, 10(3), 284-290.

[11] Vuong, Q.-H. (2021). Western monopoly of climate science is creating an eco-deficit culture. Economy, Land \& Climate Insight, 1-9.

[12] Vuong, Q.-H. (2018). The (ir)rational consideration of the cost of science in transition economies. Nature Human Behaviour, 2(1), 5.

[13] Yandle, B. (2004). Environmental Kuznets Curves: An Update. PERC. https://www.perc.org/2004/04/16/environmental-kuznets-curves/ 